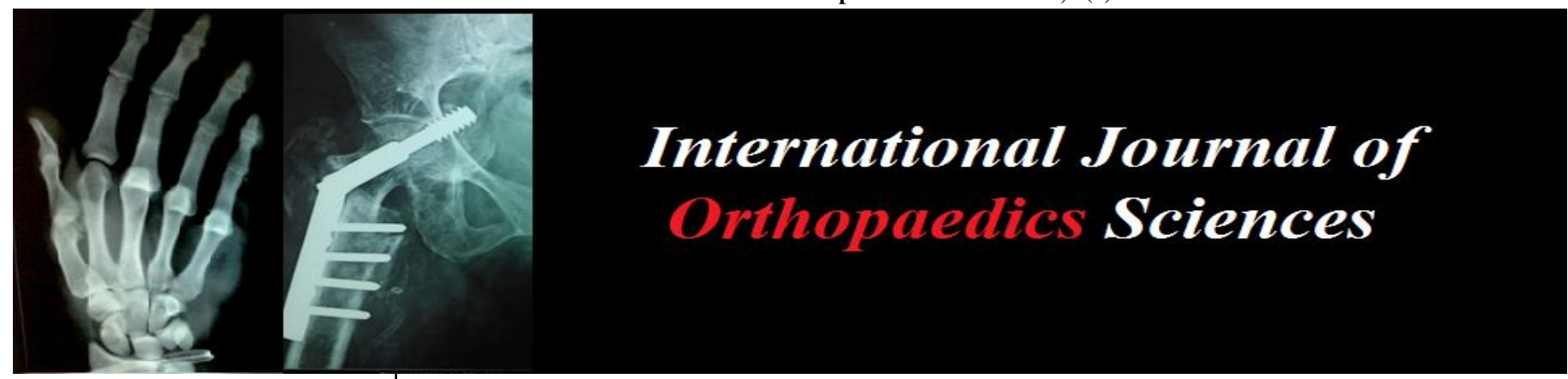

ISSN: $2395-1958$

IJOS 2019; 5(2): 710-713

(C) 2019 IJOS

www.orthopaper.com

Received: 24-02-2019

Accepted: 28-03-2019

Dr. Shri Krishan Soni

Department of Orthopaedics, RNTMC, Udaipur, Rajasthan, India

Dr. Vishnupratap singh chouhan Department of Orthopaedics, RNTMC, Udaipur, Rajasthan, India

Dr. Vinay Joshi

Professor, Department of Orthopaedics, RNTMC, Udaipur, Rajasthan, India

\section{Study of functional outcome of core decompression with platelet rich plasma enhanced cancellous bone graft in avascular necrosis of femoral head grade I and II}

\author{
Dr. Shri Krishan Soni, Dr. Vishnupratap Singh Chouhan and Dr. Vinay \\ Joshi
}

DOI: https://doi.org/10.22271/ortho.2019.v5.i2j.80

Abstract

Introduction: Avascular necrosis (AVN), most commonly affects femoral head. Etiology may be traumatic or non-traumatic. The goal of treatment is preservation of head of femur in early stages I and II by different hip preserving methods \& to delay hip arthroplasty.

Aims and Objectives: To evaluate and discuss the results of iliac crest cancellous bone graft enhanced with platelet rich plasma and core decompression in of AVN head of femur grade I and II.

Method and Materials: This study was done in Deptt of Ortho., RNT MC \& Hospital, Udaipur from 1 Oct. 2016 to 30 Sep. 2018. 25 Patients (38 hips) of both sex and aged between 25 to 50 years with AVN head of femur grade I and II were treated by core decompression with platelet rich plasma enhanced cancellous bone graft. Final results were graded according to Harris hip score.

Results: Final Results were 10 hips (26.3\%) had excellent, 17 hips (44.7\%) good, 7 hips (18.4\%) had fair and 4 hips $(10.5 \%)$ had poor result. There was improvement in mean Harris Hip Scores by 10.1 points (73.1 to 83.2).

Conclusion: Pain relief was achieved and probably due to decompression, and curettage of necrotic area. Improvement in Harris hip score and delay the need for THR.

Keywords: AVN (Avascular necrosis), PRP (Platelet rich plasma), core decompression

\section{Introduction}

Avascular necrosis (AVN) also known as Osteonecrosis or aseptic necrosis, is a particularly devastating, degenerative condition of human skeleton because of its propensity to strike young adults and its often unrelenting progression despite treatment. AVN most commonly affects femoral head, although it may involve other bones in body. Although the disease is becoming more prevalent, and various inciting factors have been recognized, the pathogenesis remains unclear and recommended forms of treatment are controversial. Various hypotheses have been suggested regarding the pathophysiologic mechanisms underlying the disease, including fat embolism, intraosseous coagulation, intraosseous stress and pressure. Changes that occur in blood flow through bone have important implications in disease. Etiology may be traumatic or non-traumatic. Head of femur is most commonly affected, because of specially peculiar blood supply pattern.

The goal of treatment of osteonecrosis of head of femur is preservation of head of femur in early stages I, II and early III by different hip preserving methods \& to delay hip arthroplasty. The present study includes the AVN head of femur in early stages- precollapse (Ficat \& Arlet 1960) stage I and II. Management consists of decompression of femoral head by drilling and removal of necrotic material in head and to interrupt the cycle of ischemic and intraosseous hypertension that may contribute to the disease, followed by filling of the space by cancellous bone graft enhanced with platelet rich plasma, depending on the site of necrosis on head of femur.

\section{Aims and Objective}

- To evaluate the results of iliac crest cancellous bone graft enhanced with platelet rich plasma
Dr. Shri Krishan Soni

Department of Orthopaedics, RNTMC, Udaipur, Rajasthan, India 
and core decompression in avascular necrosis of head of femur.

- To review the available literature on management of AVN head of femur.

- To discuss the results of "Platelet rich plasma enhanced

\section{Material and Method}

This study was conducted in Department of Orthopedics, RNT Medical College \& Hospital, Udaipur between the periods of 1st Oct. 2016 to 30th Sep. 2018. Patients of both sex and aged between 25 to 50 years admitted in orthopedics wards with avascular necrosis head of femur grade I and II were included. Final results were evaluated by pre and postoperative Harris Hip Score.

\section{Inclusion criteria}

- Patients of both sex, aged between 25 to $50 \mathrm{yrs}$

- Patients with AVN hip ficat and Arlet grade I and II

\section{Exclusion criteria}

- Patients aged <25yrs and >50 yrs

- Ficat and arlet grade III and grade IV

- Economically Poor Patients with daily basis Income.

- Patients with neuromuscular or neurodegenerative disorders.

\section{Surgical technique}

After administering appropriate anesthesia, patients were

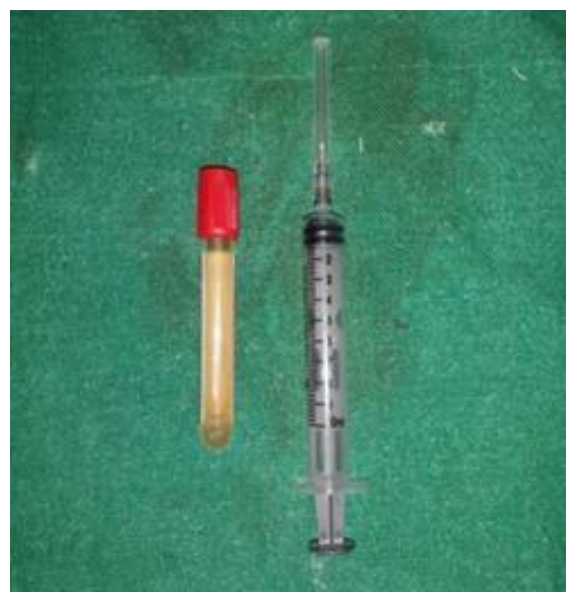

1. PRP

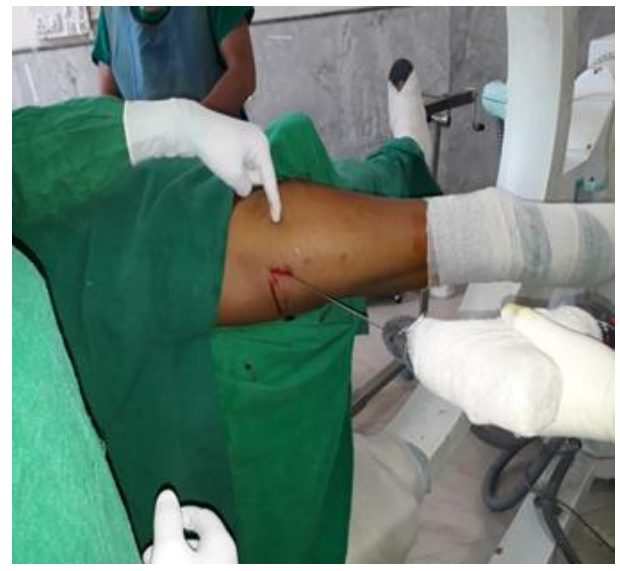

3. Guide wire and drill bit insertion placed in supine position with the ilium on the affected side is lifted $15^{\circ}$. Once the leg had been disinfected completely \& had been covered so that maneuvering could be done easily during surgery.

The os pubis, femoral artery, ASIS, iliac crest and inguinal ligament were palpated and marked on skin.

A $7.5 \mathrm{~cm}$ incision is given behind ASIS along outer lip of iliac crest. It is curved downward with its concavity towards posterior side to the level of base of greater trochanter.

A segment of iliac crest $2.5 \mathrm{~cm}$ long and $2.5 \mathrm{~cm}$ broad have been cut with help of osteotome/saw.

\section{Core decompression}

After exact location of necrotic lesion in femoral head with help of MRI, A $2 \mathrm{~cm}$ straight incision was given at the base of GT. TFL is incised in the line with skin incision. An artery foreceps inserted to separate muscle fibres up to Bone. Firstly A $3.2 \mathrm{~mm}$ long drill bit inserted and multiple drilling done in the head through subtrochanteric region under fluoroscopic guidance. Then A $6.5 \mathrm{~mm}$ drill bit used to make a tunnel from subtrochanteric area through neck up to necrotic area in head of femur. Necrotic area is removed \& biopsy material is collected. The defect in the head is filled up with PRP enhanced cancellous bone graft taken from iliac crest. In some cases adductor tenotomy is done if abduction was restricted. The foot is fitted with a boot with antirotation bar.

\section{Operative procedure}

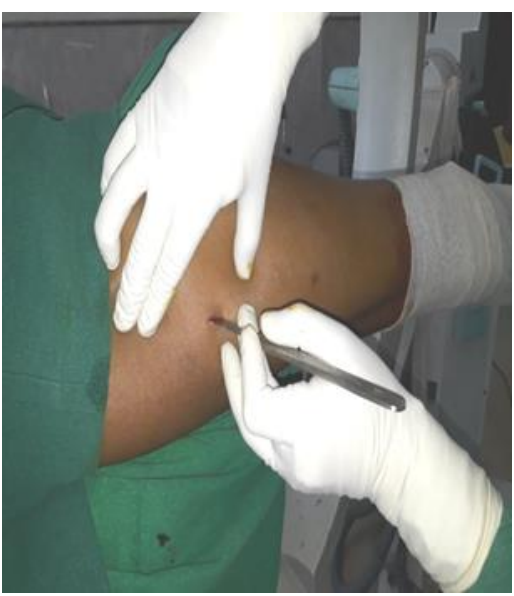

2. Position and Incision

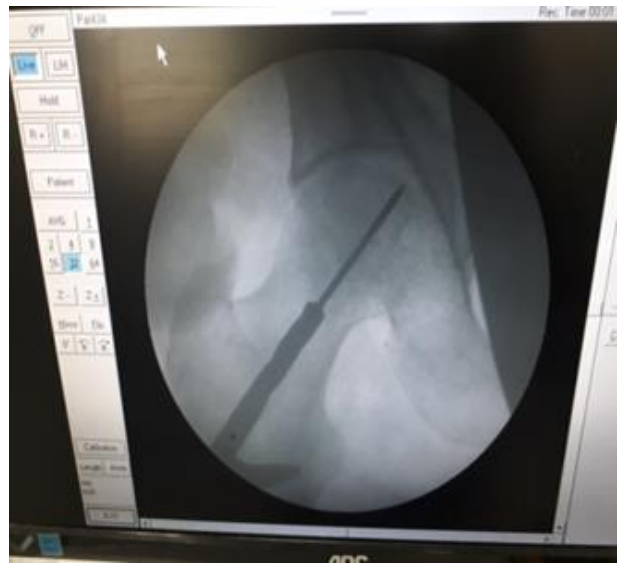

4. Guide Wire Insertion and $6.5 \mathrm{~mm}$ drill bit Insertion (C-Arm Image) 

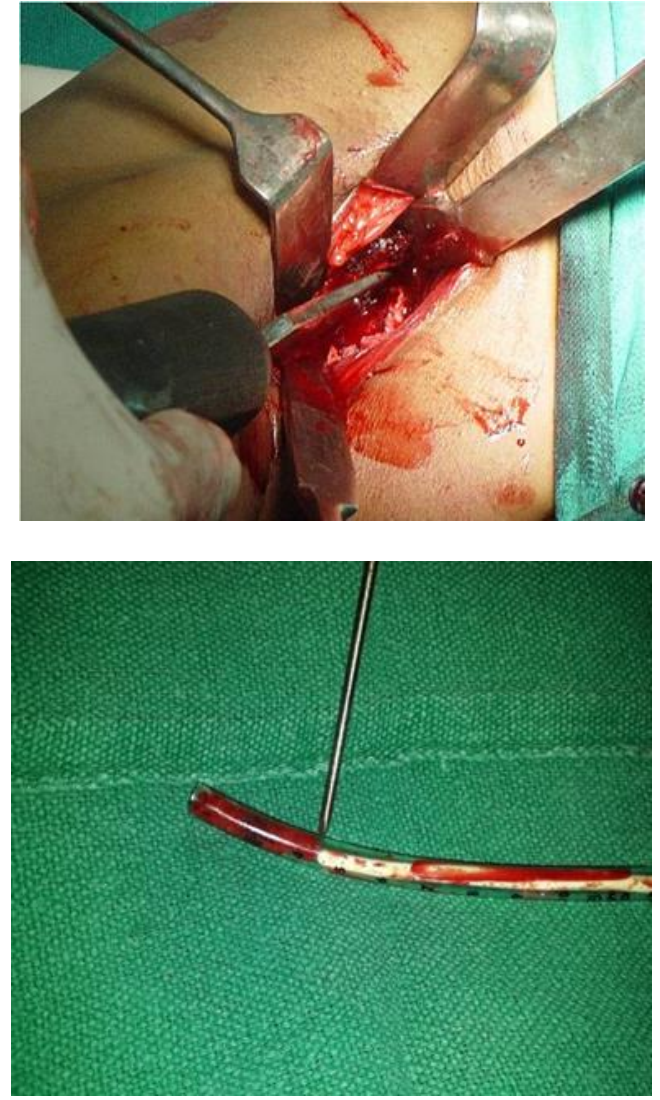

5. Iliac Crest Cancellous bone graft harvesting and 6. PRP Enhanced Bone Graft Loading in ET tube

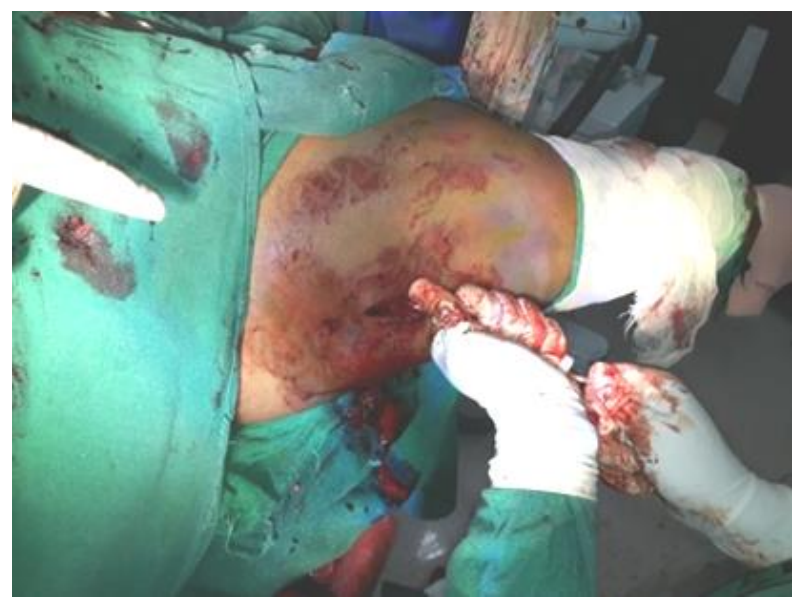

7. Bone Grafting in Decompressed Femur Head

\section{Post oerative car}

- On recovery from anaesthesia the vital parameters of patient were monitored.

- Antibiotic injections (Ceftriaxone $1 \mathrm{gm} \mathrm{BD}$ ) were given.

- Injection diclofenac sodium 2ml IM SOS.

- Wound dressing was after 48 hours. Patient was discharged with oral antibiotics, calcium and oral analgesics.

- Patient was asked to come for followup after 2 weeks for stitch removal.

- Knee bending and quadriceps exercise are started after 2 weeks.

- Non-weight bearing walking was started with help of crutches at 6 weeks.

- At 3 month, partial weight bearing was started. Radiological evaluation and hip exercise was continued.

- After 6 months, Harris hip score was measured and full weight bearing started except in cases of $H / O$ steroid intake.

\section{Results and Discussion}

- There were 25 cases (38 hips), 22 males and 3 females.

- Most of the patients (76.4\%) were in the age group of 2540 years.

- The average age in this series was 35.5 years.

- There were 13 patients $(52.0 \%)$ having both hip joint involvement and ratio of right and left was equal.

- Most common mode of the disease was non-traumatic $(60 \%)$ and most common non-traumatic cause was steroid intake in 9 cases $(36 \%)$.

- $16(64 \%)$ cases had associated medical problems, the most common being poor physical health- $9(36 \%)$ cases.

- $16(42.1 \%)$ hips had poor $<70$ points preoperative Harris Hips Scores.

- All 38 hips had stage I and II AVN (Ficat and Arlet).

- Out of 38 hips, according to Ficat and Arlet, 28 (73.7\%) hips had stage II (sclerosis and cysts) and 10 hips $(26.3 \%)$ had stage I (Normal radiologically).

- The most common postoperative complication was restriction of the hip movements in 10 hips $(26.3 \%)$ and second common was meralgia paresthetica in $2(5.3 \%)$ hips and shortening between $1-3 \mathrm{~cm}$ in 3 (7.9\%) hips.

- There was one case of deep infection and 1 case had abductor weakness.

- Four hips (10.5\%) underwent THR for collapsed femoral head and subsequent arthritic changes in follow up period.

- Final clinical results as evaluated by harris hip score were: (Grading of Harris hip score- $<70=$ poor, 7079=fair, 80-89=good, 90-100=excellent)

- Exellant -10 hips $(26.3 \%)$

- Good - 17 hips $(44.7 \%)$

- Fair - 7 hips $(18.4 \%)$

- Poor - 4 hips $(10.5 \%)$

- There was improvement in mean Harris Hip Scores by 10.1 points (73.1 to 83.2 ).

- X-ray picture of patients with AVN may not correlate with the actual clinical status of the patients. So, both radiological and clinical examination should go side by side during follow-up of a patient with AVN head of femur.

\section{Conclusion}

Pain relief achieved immediate postoperatively and was probably due to decompression, drilling and curettage of necrotic area. Movement of the hip also improved postoperatively, due to relief in pain and to the effect of adductor tenotomy and good physiotherapy. Even in presence of deformity of the femoral head, this method has better results in AVN early stages, stage I and II . This procedure can give immediate relief in pain with improvement in harris hip score and delay the need for total hip replacement

\section{References}

1. ARCO (Association Research Circulation Osseous) committee on terminology and classifications. Arco News. 1992; 4:41-6.

2. Baksi DP: Treatment of AVN of the femoral head by drilling and muscles - pedicle bone grafting. JBJS [Br]. $1991 ; 73(2): 241-5$.

3. Ficat RP. Idiopathic osteonecrosis of femoral head. Early diagnosis and treatment. JBJS. 1985; 67:3-9. 
4. Meyers MH. Osteonecrosis of femoral head treated with muscle pedicle bone graft Orthopaedic Clinics of North America. 1985; 16(4):741-5.

5. Mont MA, Hungerford DS: Current concept review nontraumatic avascular necrosis head of femur. JBJS. 1995; 77:459-74.

6. Phemister B. Treatment of necrosis of the head of femur in adult. JBJ $S$ jan. 1949; 31A:55-66.

7. Trueta J, Harrison MHM. The normal vascular anatomy of femoral head in adult man. JBJS (Br.) 1953; 35:442.

8. Werner S, Grose R. Regulation of wound healing by growth factors and cytokines. Physiol Rev. 2003; 83:835870 .

9. Yamamoto K, Hayashi J, Miyamura H, Eguchi S. A comparative study of the effect of autologous plateletrich plasma and fresh autologous whole blood on haemostasis after cardiac surgery. Cardiovascular Surgery. 1996; 4(1):9-14. 